\title{
Pemberdayaan Mahasiswa Keperawatan Dalam Upaya Promotif Peningkatan Kesehatan Lansia dengan Hipertensi di Masa Pandemik
}

\author{
Maria Imaculata Ose ${ }^{1 *}$, Fitriya Handayani ${ }^{2}$, Sulidah $^{3}, \mathrm{Aji} \mathrm{Ega}^{4}$ \\ Jurusan Keperawatan, Fakultas IImu Kesehatan Universitas Borneo Tarakan
}

*Maria Imaculata Ose

Email: onijuntak@gmail.com

Alamat:jl Amal No1

Keperawatan FIKES UBT

\section{History Artikel}

Received: diisi oleh editor Accepted: diisi oleh editor Published: diisi oleh editor

\begin{abstract}
Abstrak.
Fase pandemi covid-19 lansia menjadi populasi yang memiliki Jurusan resiko penularan yang dengan status penurunan dari fungsi tubuh. Pasien lanjut usia dengan covid-19 menunjukkan proporsi penyakit penyerta relatif lebih tinggi, dan paling umum adalah penyakit kardiovaskular aterosklerosis, hipertensi dan penyakit paru kronis. Adapun tujuan pemberdayaan mahasiswa ini di harapkan sebagai fasilitator dan edukator bagi para lansia mampu menjaga status dan meningkatkan Kesehatan terutama dengan lansia yang memiliki hipertensi dalam fase pandemic ini. Metode pelaksanaan kegiatan ini merupakan bagian dari praktek kerja lapangan, yang melibatkan pihak jurusan keperawatan dan Puskesmas sebagai wahana praktek. Mahasiswa yang memberikan edukasi dirumah para lansia dengan telah dilakukan swab antigen untuk memastikan bebas covid-19. Pelaksanaan ini dengan memperhatikan protocol Kesehatan. kegiatan meliputi tahap persiapan, pelaksanaan dan evaluasi. Indikator tercapainya kegiatan ini meningkatnya pemahaman yang mana lansia dan keluarga mampu menjelaskan kembali edukasi yang diberikan.
\end{abstract}

Kata Kunci: Covid-19, Hipertensi, Lansia, Pendidikan Kesehatan

\begin{abstract}
In the phase of the COVID-19 pandemic, the elderly become a population that has a risk of transmission with the decreased status of body functions. Elderly patients with COVID-19 showed a relatively higher proportion of comorbidities, and the most common were atherosclerotic cardiovascular disease, hypertension, and chronic lung disease. The purpose of this student empowerment is to be a facilitator and educator for the elderly to maintain status and improve health, especially with the elderly who have hypertension in this pandemic phase. The method of implementing this activity is part of the fieldwork practice, which involves the nursing department and the public health care as a vehicle for practice. Students who provide education at home for the elderly by having an antigen swab have been carried out to ensure that they are free of COVID-19. This implementation takes into account the Health protocol. activities include the stages of preparation, implementation, and evaluation. The indicator of the achievement of this activity is increasing understanding in which the elderly and their families can re-explain the education provided.
\end{abstract}

Keywords: Covid-19, Hypertension, Elderly, Health Education. 


\section{Pendahuluan}

Lansia adalah merupakan kelompok rawan dengan klasifikasi umur pada manusia yang telah menghadapi tahap akhir dari sebuah fase kehidupan. (Ose et al., 2021). Masalah Kesehatan merupakan masalah umum yang terjadi pada Sebagian besar lansia. Pada fase pandemi covid-19 lansia menjadi populasi yang memiliki resiko penularan yang dengan status penurunan dari fungsi tubuh. Berdasarkan data penelitian dari china oleh Dai et all 2021 menyebutkan bahwa pasien lanjut usia dengan covid-19 menunjukkan proporsi penyakit penyerta relatif lebih tinggi, dan paling umum adalah penyakit kardiovaskular aterosklerosis (56,5\%), hipertensi $(43,5 \%)$ dan penyakit paru kronis $(21,7 \%)$. Proporsi kasus yang parah lebih tinggi pada kelompok lansia di bandingkan pada kelompok tidak lanjut usia.

Hipertensi mempengaruhi lebih dari $40 \%$ orang dewasa di seluruh dunia dan berhubungan dengan stroke, infark miokard, gagal jantung, dan penyakit kardiovaskular lainnya. Ini juga telah terbukti menyebabkan kerusakan fungsional dan struktural yang parah pada otak, yang menyebabkan gangguan kognitif dan demensia. (Rêgo et al., 2019). Pengobatan hipertensi merupakan pengobatan yang lama dan terus menerus sepanjang Hidup. Kemenkes, memberikan rekomendasi untuk tekanan darah normal diharapkan melakukan pemeriksaan ulang 2 tahun kemudian, pada pre hipertensi di rekomendasi pemeriksaan ulang 1 tahun kemudian dan modifikasi gaya hidup. Pada Derajat 1 dengan hipertensi pastikan dalam tempo 2 bulan melakukan pemeriksaan, modifikasi pola hidup, evaluasi atau rujuk dalam tempo 1 bulan. Pada derajat 2 hipertensi bila tekanan darah > 180/110 mmHg-evaluasi dan terapi segera atau rujuk dalam tempo 1 minggu tergantung situasi dan komplikasi. Adapun tujuan pemberdayaan mahasiswa ini di harapkan sebagai fasilitator dan edukator bagi para lansia mampu menjaga status dan meningkatkan Kesehatan terutama dengan lansia yang memiliki hipertensi dalam fase pandemic ini. Selain itu kegiatan ini menjadi tahapan pembelajaran bagi mahasiswa dalam perannya sebagai calon perawat yang akan berkontribusi dalam pelayanan lansia pada masyarakat.

\section{Metode Pelaksanaan}

Metode pelaksanaan kegiatan ini merupakan bagian dari praktek kerja lapangan, yang melibatkan pihak jurusan keperawatan dan Puskesmas sebagai wahana praktek. Pelaksanaan kegiatan ini meliputi tiga tahap meliputi persiapan, pelaksanaan dan evaluasi. Pada persiapan mengidentifikasi mahasiswa. Mahasiswa yang dilibatkan adalah mahasiswa semester enam yang telah menyelesaikan matakuliah 
keperawatan gerontic sebanyak 3 sks dan mahasiswa yang telah dinyatakan negatif setelah tes swab Antigen. Selain itu dalam tahap persiapan mahasiswa diberikan pembekalan selama 1 hari. Adapun pembekalan yang diberikan meliputi materi asuhan keperawatan pada lansia dengan penyakit Hipertensi dan upaya promotif Kesehatan yang diberikan oleh dosen pengampu mata kuliah. Selanjutnya pada tahap persiapan Jurusan keperawatan melakukan koordinasi dan penyamaan persepsi pelaksanaan kepada pihak Puskesmas Karang rejo, Pantai Amal dan Karang rejo Tarakan yang menjadi wilayah kerja mahasiswa. Pelaksanaan berjalan selama dua minggu yang berlangsung pada tanggal 1 April-9 April 2021.

Tahap Pelaksanaan mahasiswa mengidentifikasi lansia yang memiliki penyakit hipertensi berdasarkan data sekunder yang dimiliki masing masing puskesmas. Tahap selanjutnya mahasiswa melakukan kunjungan rumah, dan menerapkan Proses asuhan Keperawatan gerontic. Adapun tahapan asuhan Keperawatan gerontic yang diberikan meliputi proses pengkajian atau pengumpulan data, perumusan diagnosis keperawatan, intervensi keperawatan, implementasi dan diakhir dengan tahap evaluasi. Tahap pelaksanaan kunjungan rumah lansia dilakukan sebanyak 4 kali kunjungan oleh mahasiswa. Dengan rincian kegiatan; kunjungan pertama: perkenalan dan informed consent atau permintaan persetujuan, kunjungan kedua: Pengkajian dan pengumpulan data. Kunjungan ketiga meliputi pelaksanaan intervensi dalam kegiatan ini mahasiswa memberikan edukasi dengan menggunakan leaflet, dan poster terkait manajemen perawatan lansia dengan hipertensi yang meliputi: pengenalan hipertensi, diet dalam hipertensi, pengaturan pola hidup dengan pendekatan Cerdik, dan pemeriksaan tekanan darah dengan menggunakan tensimeter dan stetoskop dan dilakukan secara berkala. Kunjungan terakhir mahasiswa melakukan evaluasi terkait dengan edukasi yang telah diberikan dengan melakukan pengkajian kembali pemahaman lansia dan keluarga terkait manajemen perawatan lansia dengan hipertensi.

\section{Hasil dan Pembahasan}

Kegiatan pelaksanaan upaya promosi Kesehatan di wilayah kerja tiga puskesmas di kota Tarakan. Kegiatan ini dilaksanakan pada 31 lansia dengan memiliki riwayat hipertensi. Adapun deskripsi lansia sebagai berikut: 
Table 1. Deskripsi Lansia

\begin{tabular}{|c|c|c|}
\hline Kategorik & $\mathrm{N}$ & Presentasi \\
\hline Perempuan & 21 & $67 \%$ \\
\hline Laki-Laki & 10 & $33 \%$ \\
\hline \multicolumn{3}{|l|}{ Usia } \\
\hline $45-59$ & 14 & $45 \%$ \\
\hline $60-74$ & 11 & $35 \%$ \\
\hline $75-90$ & 6 & $20 \%$ \\
\hline \multicolumn{3}{|l|}{ Keluhan } \\
\hline Nyeri & 30 & $96 \%$ \\
\hline Gangguan Tidur & 9 & $30 \%$ \\
\hline Kelelahan & 3 & $16 \%$ \\
\hline Defisit pengetahuan & 11 & $35 \%$ \\
\hline \multicolumn{3}{|l|}{ BMI } \\
\hline kurang dari 18,5 (kekurangan berat badan) & 3 & $11 \%$ \\
\hline 18,5-24,9 (Normal) & 16 & $50 \%$ \\
\hline 25,0-29,9 (Kelebihan Berat Badan) & 10 & $33 \%$ \\
\hline 30 atau lebih (Kegemukan/Obesitas) & 2 & $5 \%$ \\
\hline \multicolumn{3}{|l|}{ Tekanan Darah } \\
\hline Normal $<120 /<80 \mathrm{mmHg}$ & 3 & $5 \%$ \\
\hline Pra-Hipertensi 120-139 /80-89 mmHg & 8 & $27 \%$ \\
\hline Hipertensi Tingkat I 140-159 / 90-99 & 13 & $44 \%$ \\
\hline Hipertensi Tingkat II > 160/ > 100 & 7 & $22 \%$ \\
\hline \multicolumn{3}{|l|}{ Kunjungan fasilitas Kesehatan } \\
\hline Rutin & 21 & $78 \%$ \\
\hline Tidak rutin & 10 & $22 \%$ \\
\hline
\end{tabular}

Deskripsi data yang ditunjukkan pada tabel diatas yang merupakan hasil pengumpulan data menunjukan sebagian besar lansia memiliki tekanan darah hipertensi tingkat 1 dengan tensi 140-159/ 90-99 $\mathrm{mmHg}$ sebanyak $44 \%$ dan prahipertensi tingkat II sebanyak $27 \%$. Keluhan yang dialami lansia Sebagian besar defisit pengetahuan sebanyak 55\% lansia. Kepatuhan lansia dalam memeriksa Kesehatan pada fasilitas kunjungan pelayanan Kesehatan sebanyak $78 \%$ dan ada sekitar $22 \%$ lansia yang tidak rutin. Sebagian besar lansia menjelaskan bahwa memiliki kecemasan tertular apabila memeriksakan kesehatannya ke fasilitas Kesehatan baik puskesmas dan Rumah Sakit pada fase pandemic covid-19. 

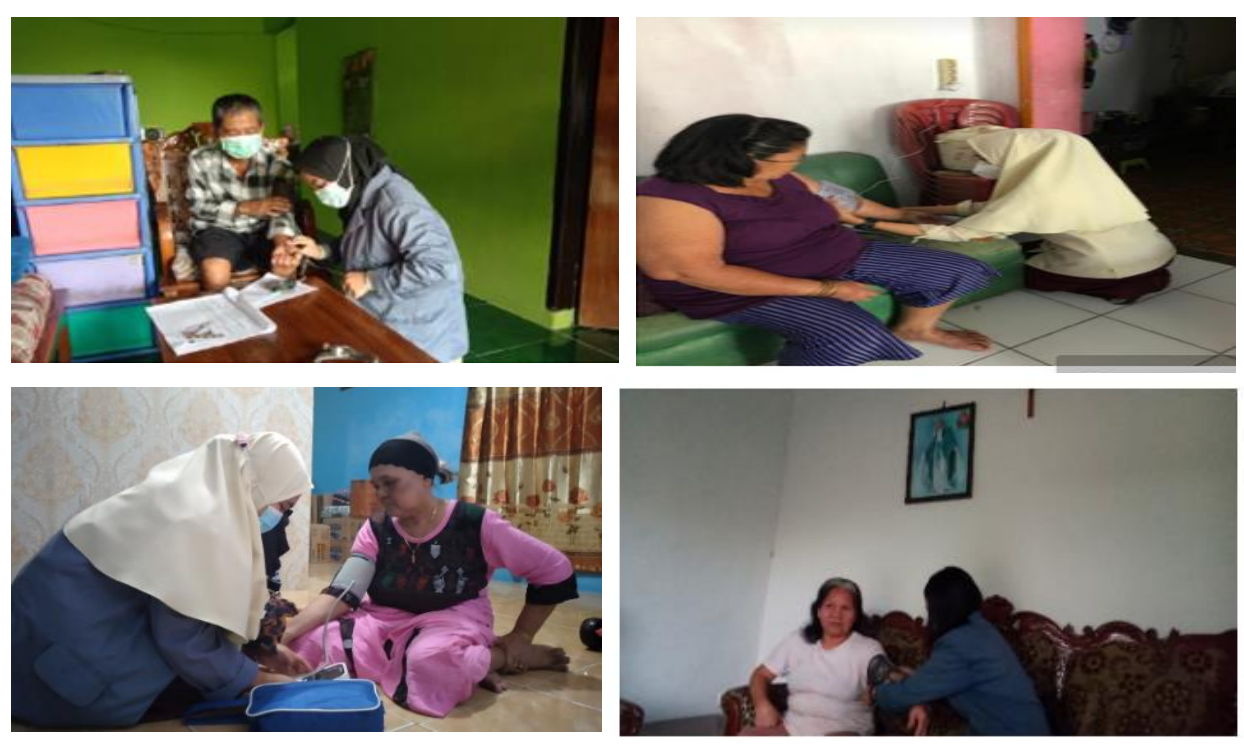

Gambar1 pemeriksaan tekanan darah

Kunjungan rumah merupakan salah satu bentuk perawatan di komunitas. Ketika perawat memasuki rumah pasien, ada harapan dari kedua belah pihak yang mempengaruhi interaksi sosial. Mempertahankan martabat pasien menuntut perawat untuk mengenal pasien dan menunjukkan rasa hormat terhadap otonomi dan integritas mereka. (Fjørtoft et al., 2021). Perawatan di rumah (Home Care Nursing/HCN) mungkin merupakan layanan yang berpotensi berharga bagi pasien (Ganann et al., 2019).
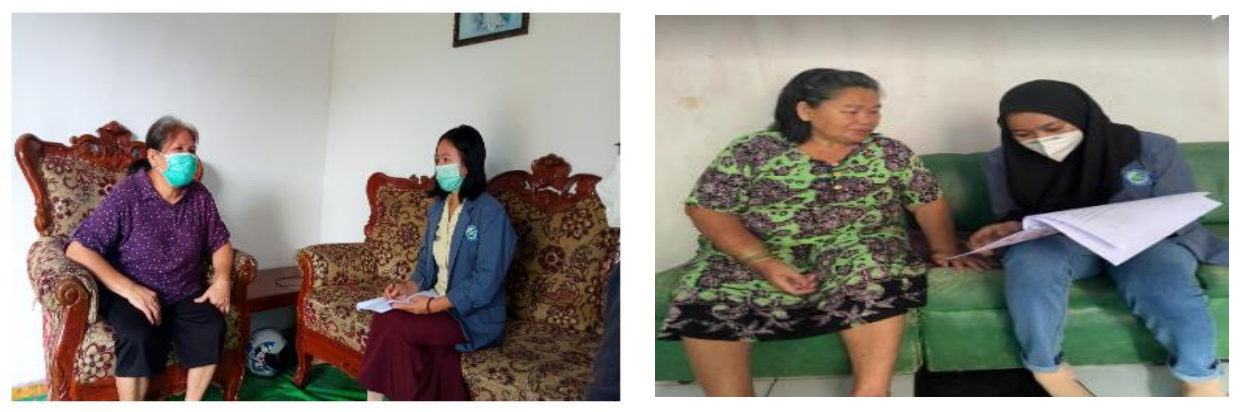

Gambar 2 pelaksanaan edukasi terkait langkah modifikasi dilaksanakan secara optimal ketika adanya interaksi dan kolaborasi antara pasien, keluarga maupun perawat yang terlibat. (Danielsen et al., 2018). Program perawatan di rumah yang berfokus pada gejala mampu membantu pasien untuk mengelola efek samping pengobatan mereka secara lebih efektif daripada perawatan standar.(Hadjisavva et al., 2021) 
Perawatan yang dilakukan dalam kegiatan ini mencakup pemeriksaan Kesehatan meliputi tekanan darah, nadi, suhu, pernafasan dan dilanjutkan edukasi. Edukasi yang diberikan pada lansia yaitu penguatan terkait dengan diet hipertensi dan aktivitas olahraga pada lansia yang dapat diterapkan dengan kondisi hipertensi. Hipertensi dapat disebabkan oleh factor diet atau makanan yang dikonsumsi. Konsumsi yang tinggi natrium, makanan padat energi, kandungan lemak, karbohidrat olahan, tambahan gula dan rendah buah dan sayuran berkontribusi pada peningkatan risiko hipertensi (HTN) dan penyakit kardiovaskular (Ozemek et al., 2018). Rekomendasi yang diberikan adalah mengadopsi diet kaya makanan nabati, bijibijian, produk susu rendah lemak, dan asupan natrium dalam batas normal dapat efektif dalam pencegahan dan pengelolaan hipertensi. Diet ini telah ditemukan lebih efektif pada orang dewasa yang lebih tua dan orang hipertensi, terutama dalam studi yang menyediakan makanan atau konseling diet yang sering. DASH adalah singkatan dari Dietary Approaches to Stop Hypertension. Ini terdiri dari jenis diet yang telah ditemukan untuk membantu menurunkan tekanan darah serta tingkat homosistein (Hashemi et al., 2019). DASH adalah cara makan yang rendah lemak hewani dan susu serta kaya akan buah dan sayuran. Ini adalah diet seimbang yang dapat diikuti oleh semua orang untuk membantu mereka menjalani gaya hidup sehat.(Morze et al., 2020).

Olahraga menjadi bagian edukasi dalam program pendampingan pada lansia. Olahraga adalah terapi tambahan yang efektif untuk manajemen hipertensi, dalam kebanyakan kasus, pengobatan lini pertama untuk mengurangi tekanan darah adalah memulai perubahan gaya hidup, di mana latihan aerobik teratur merupakan komponen utama (Sharman et al., 2019). Manfaat dari olahraga dapat mendukung penurunan volume sekuncup dan curah jantung pada orang dewasa yang lebih tua, efek olahraga ditandai dengan penurunan tekanan darah. Orang dewasa harus melakukan 150 hingga 300 menit per minggu dengan intensitas sedang atau 75 hingga 150 menit per minggu untuk latihan aerobik intensitas kuat, atau kombinasi yang setara dari latihan aerobik intensitas sedang dan kuat. Aktivitas olahraga harus melakukan aktivitas penguatan otot setidaknya 2 hari per minggu (Rêgo et al., 2019). Namun untuk pada lansia dianjurkan melakukan aktivitas olahraga sesuai dengan toleransi dari individu masing- 
masing, dan berhenti saat merasakan ketidaknyamanan seperti nyeri dada, sesak, dan pusing. Pada fase pandemi covid -19 tingginya angka penularan pada lansia, maka diberikan edukasi agar lansia juga harus meningkatkan imunitas dan mematuhi protocol Kesehatan meliputi menggunakan masker, mencuci tangan, menjauhi keramaian, menghindari keramaian dan menjaga jarak.

Tahapan evaluasi dalam kegiatan ini mengukur kembali pengetahuan, pemahaman dan pemeriksaan tekanan darah dari lansia dan melihat keterlibatan keluarga. Keterlibatan keluarga menjadi bagian penting dalam mendampingi dan membantu perawatan lansia sehari- hari. Indikator tercapainya kegiatan ini meningkatnya pemahaman yang mana lansia dan keluarga mampu menjelaskan kembali edukasi yang diberikan meliputi prinsip diet dan pola hidup sehat pada lansia yang memiliki hipertensi terutama pada masa pandemic covid-19.

\section{Kesimpulan dan Saran}

Pemberdayaan mahasiswa keperawatan dalam upaya promotive dapat dilakukan melalui kunjungan rumah (home care) terutama pada lansia yang memiliki penyakit hipertensi terutama di masa pandemic. Perawatan yang dilakukan dalam kegiatan ini mencakup pemeriksaan Kesehatan meliputi tekanan darah, nadi, suhu, pernafasan dan dilanjutkan edukasi. Edukasi yang diberikan pada lansia yaitu penguatan terkait dengan diet hipertensi dan aktivitas olahraga pada lansia yang dapat diterapkan dengan kondisi hipertensi. Keterlibatan keluarga menjadi bagian penting dalam mendampingi dan membantu perawatan lansia sehari- hari. Indikator tercapainya kegiatan ini meningkatnya pemahaman yang mana lansia dan keluarga mampu menjelaskan kembali edukasi yang diberikan meliputi prinsip diet dan pola hidup sehat pada lansia yang memiliki hipertensi terutama pada masa pandemic covid-19.

Evaluasi kegiatan menjadi suatu laporan dan masukan kepada Puskesmas sebagai bahan informasi untuk tindak lanjut pada lansia kelolahan di wilayah kerja masing- masing Puskesmas sehingga dapat meningkatkan status Kesehatan pada lansia. 


\section{Daftar Pustaka}

Danielsen, B. V., Sand, A. M., Rosland, J. H., \& Førland, O. (2018). Experiences and challenges of home care nurses and general practitioners in homebased palliative care - A qualitative study. BMC Palliative Care. https://doi.org/10.1186/s12904-0180350-0

Fjørtoft, A. K., Oksholm, T., Delmar, C., Førland, O., \& Alvsvåg, H. (2021). Home-care nurses' distinctive work: A discourse analysis of what takes precedence in changing healthcare services. Nursing Inquiry. https://doi.org/10.1111/nin.12375

Ganann, R., Weeres, A., Lam, A., Chung, H., \& Valaitis, R. (2019). Optimization of home care nurses in Canada: A scoping review. In Health and Social Care in the Community. https://doi.org/10.1111/hsc. 12797

Hadjisavva, I. C., Papastavrou, E., \& Kouta, C. (2021). Knowledge and Attitudes of Home Care Nurses in Cyprus in the Management of Cancer Pain. Home Health Care Management and Practice. https://doi.org/10.1177/108482232095 7287

Hashemi, R., Rahimlou, M., Baghdadian, S., \& Manafi, M. (2019). Investigating the effect of DASH diet on blood pressure of patients with type 2 diabetes and prehypertension: Randomized clinical trial. Diabetes and Metabolic Syndrome: Clinical Research and Reviews.

https://doi.org/10.1016/j.dsx.2018.06.0 14

Morze, J., Danielewicz, A., Hoffmann, G., \&
Schwingshackl, L. (2020). Diet Quality as Assessed by the Healthy Eating Index, Alternate Healthy Eating Index, Dietary Approaches to Stop Hypertension Score, and Health Outcomes: A Second Update of a Systematic Review and Meta-Analysis of Cohort Studies. Journal of the Academy of Nutrition and Dietetics. https://doi.org/10.1016/j.jand.2020.08.0 76

Ose, M. I., Handayani, F., Pujianto, A., Sulfiana, M., \& Ega, A. (2021). Peningkatan Kualitas Caregiver Melalui Pelatihan Kegawatdaruratan dan Dasar di masa pandemic covid-19 Perawatan. 3.

Ozemek, C., Laddu, D. R., Arena, R., \& Lavie, C. J. (2018). The role of diet for prevention and management of hypertension. In Current Opinion in Cardiology.

https://doi.org/10.1097/HCO.00000000 00000532

Rêgo, M. L. M., Cabral, D. A. R., Costa, E. C., \& Fontes, E. B. (2019). Physical Exercise for Individuals with Hypertension: It Is Time to Emphasize its Benefits on the Brain and Cognition. Clinical Medicine Insights: Cardiology. https://doi.org/10.1177/117954681983 9411

Sharman, J. E., Smart, N. A., Coombes, J. S., \& Stowasser, M. (2019). Exercise and sport science australia position stand update on exercise and hypertension. In Journal of Human Hypertension.

https://doi.org/10.1038/s41371-0190266-z 